\title{
Capsular Blockage Syndrome: Clinical and Anterior Segment Optical Coherence Tomography (OCT) Characteristics
}

\author{
Hsin-Yu Yang \\ Taipei Veterans General Hospital \\ Sui-Ching Kao \\ Taipei Veterans General Hospital \\ Chieh-Chih Tsai \\ Taipei Veterans General Hospital \\ Wei-Kuang Yu ( $\sim$ wkyu3@vghtpe.gov.tw) \\ Taipei Veterans General Hospital
}

\section{Research Article}

Keywords: Capsular blockage syndrome, optical coherence tomography, laser capsulotomy

Posted Date: June 1st, 2021

DOI: https://doi.org/10.21203/rs.3.rs-557637/v1

License: (ㄷ) (i) This work is licensed under a Creative Commons Attribution 4.0 International License. Read Full License 


\section{Abstract}

Background:

CBS is a rare phenomenon which is found during and after cataract surgery. The mechanism, OCT presentation and clinical characteristics are not well studied.

\section{Methods:}

Document patients with CBS who underwent examination, including refraction, best-corrected visual acuity, slit lamp, anterior segment OCT, and onset after cataract surgery. All patients underwent Nd:YAG laser capsulotomy and were prescribed a low-dose topical steroid for seven days. Postcapsulotomy refraction and visual acuity were recorded.

\section{Results:}

This study included 18 eyes. Patients' mean age was 80 (range, 54-92). The duration between cataract surgery and CBS diagnosis ranged 15-136 months. According to anterior segment OCT findings, we subcategorized the patients into four types: minimally opaque ( $n=4,22 \%)$, uniformly turbid $(n=7,39 \%)$, focally condensed $(n=5,28 \%)$, and diffused sparkling $(n=2,11 \%)$. After laser capsulotomy, mean visual acuity improved $0.18 \pm 0.09$ on the LogMar. A significant difference in absolute refraction changes between the groups was noted-maximum in the focally condensed and minimum in the uniformly turbid types. No patient developed complications or needed further treatment for CBS during mean follow-up of 80 months.

\section{Conclusion:}

High-resolution anterior segment OCT is useful for analyzing pathological changes in the CBS. Our study implies that these four types of CBS presentation indicate various causes of late-CBS formation, as well as distinct clinical presentation and post-laser capsulotomy outcome. In addition, YAG laser capsulotomy is a safe late-CBS treatment modality.

\section{Background}

Capsular blockage syndrome (CBS) is a phenomenon in which fluid accumulates between the continuous curvilinear capsulorrhexis (CCC) margin and posterior capsule. It can be categorized into three clinical types according to the timing and mechanism:(1) intraoperative, acute, and late-onset CBS. Intraoperative CBS occurs during the step of hydrodissection in cataract surgery. It is transient and can be resolved by releasing the pressure by spinning or dissecting the crystalline lens. Acute CBS occurs in less than two weeks. The mechanism has been proposed as retained viscoelastic material or other inflammatory pathways creating the osmotic gradient, dragging fluids between the intraocular lens and posterior capsular bag. In addition, fulminant inflammation can cause ciliary body swelling and formation of the pupillary membrane, blocking the outflow fluid from the capsular space.(2) Anterior rotation of the lens diaphragm may lead to a myopic shift, elevated intraocular pressure and decreased visual acuity. In contrast to acute CBS, late CBS may not result in significant symptoms unless decreased vision is expressed by the patient. It is believed to develop due to lens epithelial proliferation or latent infection (such as Propionibacterium acnes). $(3,4)$ Clinicians will find whitish turbulent fluid trapped in a space between the posterior intraocular lens and posterior capsule. $(5,6)$ Some cases will show crystal-like material in that particular space, which could be an Elschnig pearl, the result of lens epithelial cell proliferation, or others such as alpha crystalline or albumin. $(7,8)$

Previous reports on late CBS are few, and most are case reports. Here we have conducted a study of CBS in a medical center from 2012 to 2019 . The highlight of the study is that this is the first study that comprehensively documents CBS with high-resolution anterior segment optical coherence tomography (OCT). Furthermore, we categorized the findings into different subtypes. Clinical presentation, pathophysiology, treatment, and outcomes are documented and discussed in this study.

\section{Methods}

We collected patients who had undergone cataract surgery and were found to have CBS from 2012 to 2019 in Taipei Veterans General Hospital. Basic data including age, sex, visual acuity before and after treatment, refraction before and after treatment, axial length, type of intraocular lens implanted, and duration between cataract surgery and detection of late CBS were recorded. Patients' eyes were photographed using a slit lamp. We chose anterior segment OCT (Optovue, U.S.) as a supplementary tool to evaluate the thickness and sagittal cut image of capsular blockage syndrome. The distance between the intraocular lens and capsular bag was defined as the length of a perpendicular line to the center of the above two mentioned. All the patients were treated with neodymium-doped yttrium aluminum garnet (Nd:YAG) laser capsulotomy. A fluorometholone $0.02 \%$ eye drop was given four times a day for seven days after laser treatment. Patients were followed up for 45 minutes, then in one week, and one month after laser treatment. Complications such as intraocular lens breaks by laser, lens dislocation, elevated intraocular pressure, recurrence of capsular blockage syndrome, and endophthalmitis were checked during each visit.

All statistical analyses were performed using SPSS Statistics (Statistical Product and Service Solutions, version 22, International Business Machines Corporation). Kruskal-Wallis test was used for analyzing non-parametric data. Significance was considered if the $p$ value was less than 0.05. 


\section{Results}

In total, we collected 18 cases. The descriptive analysis is shown in Table 1 . The average age was 80 , the oldest was 92 , and the youngest was 54 . There was no sexual predominance; the male-to-female ratio was 1 . All the patients presented blurred vision or decreased visual quality as chief complaints. The mean duration between cataract surgery and detection of capsular blockage syndrome was 80 months, ranging from 15 to 136 months. Hydrophobic intraocular lens predominated in this study, accounting for $94 \%$ of our cases. A slit lamp exam and anterior segment OCT were performed on all patients. The distance between the intraocular lens posterior surface and posterior capsule ranged from $308 \mathrm{~mm}$ to $701 \mathrm{~mm}$.

We have categorized late CBS into four subtypes according to slit lamp and OCT findings: minimally opaque ( $n=4,22 \%$. Figs $1 A$ and $1 B$ ), uniformly turbid ( $n=7,39 \%$. Figs $2 A$ and $2 B)$, focally condensed type $(n=5,28 \%$. Figs $3 A$ and $3 B)$, and diffused sparkling $(n=2,11 \%$. Figs $4 A$ and $4 B)$.

The minimally opaque type showed high translucency and mild reflectivity of the fluid between the intraocular lens and posterior capsule in slit lamp and OCT. Very few high-signal materials were found near the posterior capsule. Upon presentation, mean visual acuity was $0.23 \pm 0.04$ on the LogMar. The mean LogMAR visual acuity of these patients improved $0.20 \pm 0.07$ after laser capsulotomy. Mean absolute refraction change after laser capsulotomy was $0.31 \pm 0.11$.

The uniformly turbid type appears to be a more classic finding in CBS, which features milky fluid trapped inside the space between the intraocular lens and posterior capsule. The fluid yielded gray and medium-high signals in slit lamp and OCT, respectively. It was found as early as 15 months after cataract surgery. The mean LogMAR visual acuity was $0.37 \pm 0.15$ and improved $0.19 \pm 0.08$ after laser capsulotomy in the seven cases. After laser capsulotomy, mean absolute refraction change was $0.05 \pm 0.06$, significantly less than in other groups.

The focally condensed type manifests as a thick, cloudy aggregation laying in the periphery inside the capsular space. In addition, thick fluid can be found. The five cases of this type developed CBS 44 to 120 months after cataract surgery. The mean LogMAR visual acuity showed $0.3 \pm 0.06$ at presentation and improved $0.23 \pm 0.04$ after laser capsulotomy. Mean absolute refraction change after laser treatment was $0.68 \pm 0.39$, significantly larger than seen in the other groups.

The diffused sparkling type is characterized by crystalline-like materials distributed in the space between the intraocular lens and posterior capsule. Two of our cases showed this presentation. The interval between cataract surgery and laser capsulotomy was 84 and 108 months, respectively, in these two cases. Mena visual acuity before laser treatment was $0.15 \pm 0.05$ on the LogMar. Both patients showed no change in vision after laser treatment. Mean absolute refraction change was $0.19 \pm 0.06$ in the two patients.

All the parameters were included in a Kruskal-Wallis test to calculate the difference between the four subtypes. Table 2 shows comparison of the clinical parameters between the four groups. There was no noted significant difference in age, interval between CBS and cataract surgery, axial length, distance between the IOL and posterior capsular bag or refraction shift in the four groups. The refraction shift after laser capsulotomy in the four subtypes is shown in Fig 5. Minimally opaque type, focally condensed type and diffused sparkling type are more prone to showing myopic refraction shift, while the uniformly turbid type usually shows a mild hyperopic shift or no refraction shift after laser capsulotomy. There was a significantly lower absolute refraction change in the uniformly turbid group, and a higher absolute refraction change in the focally condensed group. All the patients successfully received YAG laser capsulotomy. Mean LogMAR visual acuity improved $0.18 \pm 0.09$. The mean follow-up time was 80 months, ranging from 1 to 1,080 months. No patient developed laser-associated complications such as lens break, lens dislocation, elevated intraocular pressure, refractory inflammation, cystoid macular edema, recurrence of CBS or endophthalmitis. No patients received vitrectomy as primary treatment, or further treatment.

\section{Discussion}

CBS is a rare complication of cataract surgery.(9) Previous studies looked at CBS with slit lamp photography, and some with ultrasound biomicroscopy. This study is the first to comprehensively record CBS with anterior segment OCT. The cross-sectional image compiling multiple interference patterns from light reflected on the intraocular layers can better display the anterior segment image.(10) It can also be used to identify the slope and deflection of the intraocular lens optical region relative to the pupil plane(11) and sizing of the implantable collamer lens, indicating its accuracy and convenience.(12) Besides slit lamp examination, anterior segment OCT can help differentiate the substance lying between the intraocular lens and posterior capsule more clearly, compared with ultrasound biomicroscopy.

The categorization of CBS according to timing, clinical findings, mechanism and treatment is summarized in Table 3. Intraoperative CBS is caused by surgical manipulation during hydrodissection in cataract surgery. Acute CBS develops within two weeks following cataract surgery. Late CBS develops much later.

Previous classification of CBS was proposed by Kim et al.(13) They classified CBS into three groups according to their distinct clinical characteristics: noncellular, inflammatory, and fibrotic CBS. Noncellular CBS includes translucent fluid trapped in the posterior capsular bag. It is thought to be caused by retained viscoelastic materials and developed in the very early post-operative period. Inflammatory CBS is presented with prominent anterior chamber reaction in the early postoperative period and can be treated with anti-inflammatory medication. Fibrotic CBS is assumed to be caused by 
lens epithelial cell proliferation and pseudometaplasia. It is usually formed months to years after surgery. By definition, noncellular and inflammatory CBS belong to early CBS, and fibrotic CBS belongs to late CBS.

In our study, the four different types of CBS shown-minimally opaque, uniformly turbid, diffused sparkling, and focally condensed-indicate that the mechanism behind late CBS might vary. The distance between the posterior intraocular lens surface and posterior capsule ranged from $308 \mathrm{~mm}$ to $701 \mathrm{~mm}$, implying that CBS might not be truly "fibrotic" as the bag could still be distended as deep as $701 \mathrm{~mm}$. "Proliferative," rather than "fibrotic," is a better description for late CBS.

It is possible that the substances between the IOL and posterior capsular bag are different in the four groups and thus cause a distinct optical and refraction effect. The distended bag behind the intraocular lens forms a convex contour. The overall density and evenness of the substance in this convex contour may create various refractive effect, accounting for different refraction changes after Nd:YAG capsulotomy. The substance of the minimally opaque and diffused sparkling types may show even distribution and a refractive index mildly lower than vitreous and aqueous, so mild myopic refraction change was noted after laser capsulotomy. The materials in the uniformly turbid type also showed equal distribution, and they may create a higher or equal refractive index compared to those of vitreous and aqueous. Thus, this type of patient showed no or mild hyperopic refraction shift after laser treatment. In contrast, the substance in the focally condensed type may show an unequal distribution and a different refractive index from vitreous and aqueous, so absolute refraction change was significantly larger than the other groups.

According to the literature, late CBS can develop in a patient as young as seven years old. One such patient developed CBS four months after cataract surgery.(2) On the other hand, it can also develop in an 89-year-old patient who was found to have late CBS 20 years after surgery.(14) In our research, the ages range from 54 to 92 , and the incubation time was between 15 and 136 months. Compared to acute CBS, late CBS does not lead to obvious visual manifestation such as vision change, refraction change, intraocular pressure elevation, or shallow anterior chamber.(15)

There are only a few studies documenting the axial length and intraocular lens design in CBS cases. Kim et al. believes that patients with longer axial length and an intraocular lens with four haptics are more likely to develop CBS.(13) Three piece,(16) trifocal toric,(17) accommodating(18) and hydrophylic(6) lenses were also reported. Our study reveals that most CBS patients have a normal axial length ( $23.63 \pm 1.23 \mathrm{~mm})$, and they were implanted with foldable one-piece hydrophobic lenses with two haptics. The intraocular lens dominance in this study might be due to local market preferences.

While the mechanism of intraoperative and acute CBS is well understood, the mechanism behind late CBS is still a mystery. The substance between the intraocular lens and posterior capsule might be different from that of acute CBS, as it causes only a few refraction changes or swelling of the ciliary body. Though some studies have posed a possibility of insidious infection such as Propionibacterium acnes, $(3,4)$ there has been no strong evidence presented to support this hypothesis. Raina et al.(19) performed a 25-gauge vitrectomy to get the specimen and culture. Both aerobic and anaerobic cultures yielded negative results for 14 days in three cases of late CBS. Rena et al. aspired the milky fluid and culture yielded no growth of any microbes.(5) In our study, we found no conjunctival congestion, corneal keratic precipitate, anterior chamber cells, plaque-like material coating around the intraocular lens, or flare-up of inflammation after YAG capsulotomy. Furthermore, we did not prescribe any antibiotics after YAG capsulotomy, but rather a low-dose topical steroid. In the event of indolent infection, there would be infection-associated inflammation after laser treatment, which results in the releasing of toxins and the infection source into the vitreous.

Another hypothesis for the mechanism of late CBS is lens epithelial cell proliferation. This can be supported by the slit lamp and anterior segment OCT images in our study, which showed focally condense materials in front of the posterior capsule (Fig 3). These materials may release fluid by selfdegradation or drag turbid fluid inside the posterior capsular space by osmotic gradient. Nevertheless, some of the images showed few or no so-called proliferative materials around the posterior capsule (Figs 1 and 2). The diffused sparkling subtype CBS (Fig 4) indicates that there might be some other mechanism or substance inside that space. The hyper-reflective and diffusely distributed materials surprisingly do not affect vision according to our study results. The situation is similar in patients with asteroid hyalosis. The factors that determined which patient shows diffusely distributed particles, solutes or precipitate-like materials inside the capsular space are still mysteries.

Surgeons have taken the specimen between the capsular bag and intraocular lens for further analysis. Alpha-crystallin,(6, 7, 19) beta-crystallin, ${ }^{5}$ albumin, $(7,20)$ collagen,(19) calcium,(6) sodium hyruronate,(21) and globulin fractions(20) were found in the previous literature. Some of the substances were assumed to be released from lens epithelial cells.(19) These various results imply that there are different mechanisms behind capsular blockage syndrome formation. Different materials found in that space also explain why there are different types of presentation in anterior segment OCT.

Treatment of CBS includes anti-inflammatory medication for inflammatory CBS, Nd:YAG capsulotomy and surgical intervention. Gilhotra et al.(16) and Koh et al.(22) reported recurrence of CBS one week and 10 months after YAG capsulotomy, respectively. Capsular fluid aspiration(4, 5, 23) and vitrectomy(6) can be performed if laser treatment fails,(6) for refractory cases or cases that need specimens for analysis. All our patients, no matter which subtypes in anterior segment OCT, received laser capsulotomy without complications, and mean visual acuity improved $0.18 \pm 0.09$ on the LogMar.

The limitation of this study includes a small study number because this is a rare complication after cataract surgery. The case number might be underestimated as late CBS is usually asymptomatic, and thus medical help is typically not sought out. Some doctors might also overlook such cases

Page $4 / 10$ 
as the clinical appearance is not obvious. The follow-up period in this study was only one month, unless patients had ocular disease such as dry eye, retinal problem, glaucoma, etc.

\section{Conclusions}

This is the first study that comprehensively documents CBS with anterior segment OCT. High-resolution anterior segment OCT is a useful tool for detecting structural changes in CBS. We analyzed late CBS patients with high-resolution OCT and categorized them into four groups: minimally opaque, uniformly turbid, diffused sparkling, and focally condensed types. The mechanism of late CBS formation is unknown, but, in our study, the occurrence of indolent infection was less seen. Our study implies that these four types of CBS may result from various causes with different optical impacts, and Nd:YAG laser capsulotomy is a safe treatment modality for late CBS.

\section{Declarations}

\section{Ethics approval and consent to participate}

The protocol has been approved by the Institutional Review Board of Taipei Veterans General Hospital and supervised by $\square$ the Institutional Review Board of Taipei Veterans General Hospital邓. After the review by Human Research Protection Center, the implementation of the protocol is approved. All the methods were carried out in accordance with relevant guidelines and regulations and informed consent was obtained from all participants in the study.

\section{Consent for publication}

NA

\section{Availability of data and materials}

The datasets used and/or analysed during the current study available from the corresponding author on reasonable request.

\section{Competing interests}

All authors have declared no conflict of interest.

\section{Funding}

There is no funding is the study

\section{Authors' contributions}

Sui-Ching Kao and Chieh-Chih Tsai helped in data collection. Hsin-Yu Yang and Wei-Kuang Yu wrote the main manuscript text. All authors reviewed the manuscript.

\section{Acknowledgements}

Nil

\section{References}

1. Miyake K, Ota I, Ichihashi S, Miyake S, Tanaka Y, Terasaki H. New classification of capsular block syndrome. J Cataract Refract Surg. 1998;24(9):1230-4.

2. Medsinge A, Nischal KK. Capsular blockage syndrome in a child: a case report. Eye (Lond). 2013;27(11):1333-4.

3. Kollias AN, Vogel MA, de Kaspar HM, Lackerbauer CA, Grueterich M. Propionibacterium acnes in capsular bag distension syndrome. J Cataract Refract Surg. 2010;36(1):167-9.

4. Dhaliwal DK, Farhi P, Eller AW, Kowalski RP. Late Capsular Block Syndrome Associated With Propionibacterium acnes. Archives of Ophthalmology. 2011;129(2):246-7.

5. Rana M, Jiang L, Ilango B, Yang YC. Late-Onset Capsular Block Syndrome: Unusually Delayed Presentation. Case Reports in Ophthalmology. 2013;4(3):299-302.

6. Bao YZ, Pei XT, Li MW, Li XX. Late postoperative capsular block syndrome versus liquefied after-cataract. J Cataract Refract Surg. 2008;34(10):1799-802.

7. Eifrig DE. Capsulorhexis-related lacteocrumenasia. J Cataract Refract Surg. 1997;23(3):450-4.

8. Nishi O, Nishi K, Takahashi E. Capsular bag distention syndrome noted 5 years after intraocular lens implantation. Am J Ophthalmol. 1998;125(4):545-7. 
9. Holtz SJ. Postoperative capsular bag distension. J Cataract Refract Surg. 1992;18(3):310-7.

10. Zhang T, Sun CQ, Lin YB, Schallhorn JM. Rifabutin corneal deposits localized to the deep stroma using anterior segment optical coherence tomography. Am J Ophthalmol Case Rep. 2020;18:100701.

11. Kulikov AN, Danilenko EV, Dzilikhov AA. [Algorithm for predicting axial displacement of the optic part of IOL after phacoemulsification]. Vestn Oftalmol. 2020;136(2):38-43.

12. Nakamura T, Isogai N, Kojima T, Yoshida Y, Sugiyama Y. Optimization of implantable collamer lens sizing based on swept-source anterior segment optical coherence tomography. J Cataract Refract Surg. 2020;46(5):742-8.

13. Kim HK, Shin JP. Capsular block syndrome after cataract surgery: clinical analysis and classification. J Cataract Refract Surg. 2008;34(3):35763.

14. Plemel DJA, Benson MD, Rayat JS, Greve MDJ, Tennant MTS. Capsular block syndrome 20 years post-cataract surgery. Can J Ophthalmol. 2018;53(6):e222-e4.

15. Vélez M, Velásquez LF, Rojas S, Montoya L, Zuluaga K, Balparda K. Capsular block syndrome: a case report and literature review. Clinical Ophthalmology (Auckland, NZ). 2014;8:1507-13.

16. Gilhotra JS, Maloof A. Spontaneous closure of Nd:YAG posterior capsulotomy in capsular blockage syndrome. Eye (Lond). 2006;20(4):505-6.

17. Khattak A. Bilateral early capsular block syndrome following implantation of the new trifocal toric lens. Oman J Ophthalmol. 2017;10(3):238-40.

18. Alessio G, L'Abbate M, Boscia F, La Tegola MG. Capsular block syndrome after implantation of an accommodating intraocular lens. J Cataract Refract Surg. 2008;34(4):703-6.

19. Raina UK, Bhushan G, Arora S, Rathie N. A rare case of delayed onset capsular block syndrome managed using 25-gauge vitrector. Oman Journal of Ophthalmology. 2015;8(3):183-4.

20. Namba H, Namba R, Sugiura T, Miyauchi S. Accumulation of milky fluid: a late complication of cataract surgery. J Cataract Refract Surg. 1999;25(7):1019-23.

21. Sugiura T, Miyauchi S, Eguchi S, Obata H, Nanba H, Fujino Y, et al. Analysis of liquid accumulated in the distended capsular bag in early postoperative capsular block syndrome. J Cataract Refract Surg. 2000;26(3):420-5.

22. Koh JS, Song YB, Wee WR, Han YK. Recurrent late-onset fibrotic capsular block syndrome after neodymium-yttrium-aluminum-garnet laser anterior capsulotomy: a case report. BMC Ophthalmol. 2016;16:86.

23. Bergamo VC, Nakayama LF, Yamada VH, Marujo FI. A case of late-onset capsular block syndrome and its surgical treatment. Arq Bras Oftalmol. 2019;82(2):149-51.

\section{Tables}

Table 1: Patient profile and descriptive analysis 


\begin{tabular}{|c|c|c|c|c|c|c|c|c|c|}
\hline \multirow[t]{2}{*}{ Patient/sex/age(y) } & \multirow{2}{*}{$\begin{array}{l}\text { Time from } \\
\text { cataract } \\
\text { surgery to } \\
\text { YAG(months) }\end{array}$} & \multirow[t]{2}{*}{ IOL Type } & \multirow[t]{2}{*}{$A X L$} & \multirow{2}{*}{$\begin{array}{l}\text { IOL/PC } \\
\text { distance } \\
\text { (um) }\end{array}$} & \multirow{2}{*}{$\begin{array}{l}\text { CBS } \\
\text { subtype }\end{array}$} & \multirow{2}{*}{$\begin{array}{l}\text { Refraction } \\
\text { shift after } \\
\text { YAG }\end{array}$} & \multicolumn{2}{|l|}{ BCVA } & \multirow{2}{*}{$\begin{array}{l}\text { Follow } \\
\text { up time } \\
\text { (months) }\end{array}$} \\
\hline & & & & & & & $\begin{array}{l}\text { Before/After } \\
\text { YAG }\end{array}$ & improvement & \\
\hline 1/F/76 & 82 & hydrophobic & NA & 472 & $\begin{array}{l}\text { minimally } \\
\text { opaque }\end{array}$ & -0.5 & $0.22 / 0.1$ & -0.12 & 41 \\
\hline $2 / F / 75$ & 15 & hydrophobic & 23.47 & 308 & $\begin{array}{l}\text { minimally } \\
\text { opaque }\end{array}$ & -0.25 & $0.22 / 0.05$ & -0.17 & 39 \\
\hline 3/F/71 & 26 & hydrophobic & 22.74 & 450 & $\begin{array}{l}\text { minimally } \\
\text { opaque }\end{array}$ & -0.25 & $0.3 / 0$ & -0.3 & 25 \\
\hline 4/F/88 & 96 & hydrophobic & 22.4 & 375 & $\begin{array}{l}\text { minimally } \\
\text { opaque }\end{array}$ & 0.25 & $0.22 / 0$ & -0.22 & 25 \\
\hline $5 / M / 86$ & 15 & hydrophilic & 26.81 & 435 & $\begin{array}{l}\text { uniformly } \\
\text { turbid }\end{array}$ & 0.125 & $0.3 / 0.15$ & -0.15 & 1 \\
\hline 6/M/91 & 136 & hydrophobic & NA & 432 & $\begin{array}{l}\text { uniformly } \\
\text { turbid }\end{array}$ & 0 & $0.4 / 0.22$ & -0.18 & 1 \\
\hline $7 / \mathrm{M} / 80$ & 40 & hydrophobic & 23.63 & 407 & $\begin{array}{l}\text { uniformly } \\
\text { turbid }\end{array}$ & 0 & $0.7 / 0.4$ & -0.3 & 41 \\
\hline $8 / M / 54$ & 91 & hydrophobic & 26.23 & 475 & $\begin{array}{l}\text { uniformly } \\
\text { turbid }\end{array}$ & 0 & $0.3 / 0$ & -0.3 & 1 \\
\hline $9 / M / 87$ & 125 & hydrophobic & 23.2 & 614 & $\begin{array}{l}\text { uniformly } \\
\text { turbid }\end{array}$ & 0 & $0.4 / 0.22$ & -0.18 & 15 \\
\hline 10/F/82 & 108 & hydrophobic & 22.91 & 701 & $\begin{array}{l}\text { uniformly } \\
\text { turbid }\end{array}$ & 0.125 & $0.3 / 0.22$ & -0.08 & 22 \\
\hline 11/M/79 & 120 & hydrophobic & 23.45 & 550 & $\begin{array}{l}\text { uniformly } \\
\text { turbid }\end{array}$ & 0.125 & $0.15 / 0$ & -0.15 & 1 \\
\hline $12 / \mathrm{M} / 80$ & 120 & hydrophobic & NA & 550 & $\begin{array}{l}\text { focally } \\
\text { condensed }\end{array}$ & 0.125 & $0.15 / 0$ & -0.15 & 1 \\
\hline $13 / \mathrm{M} / 91$ & 84 & hydrophobic & NA & 476 & $\begin{array}{l}\text { focally } \\
\text { condensed }\end{array}$ & -0.875 & $0.3 / 0.05$ & -0.25 & 83 \\
\hline $14 / F / 76$ & 103 & Hydrophobic & 23.3 & 392 & $\begin{array}{l}\text { focally } \\
\text { condensed }\end{array}$ & -1.25 & $0.4 / 0.15$ & -0.25 & 43 \\
\hline 15/F/79 & 48 & hydrophobic & 23.15 & 403 & $\begin{array}{l}\text { focally } \\
\text { condensed }\end{array}$ & -0.375 & $0.3 / 0.05$ & -0.25 & 3 \\
\hline 16/F/79 & 44 & hydrophobic & 23.22 & 518 & $\begin{array}{l}\text { focally } \\
\text { condensed }\end{array}$ & 0.75 & $0.3 / 0.05$ & -0.25 & 3 \\
\hline 17/M/92 & 108 & hydrophobic & 22.84 & 630 & $\begin{array}{l}\text { diffuse } \\
\text { sparkling }\end{array}$ & -0.125 & $0.1 / 0.1$ & 0 & 14 \\
\hline $18 / F / 66$ & 84 & hydrophobic & 23.43 & 435 & $\begin{array}{l}\text { diffuse } \\
\text { sparkling }\end{array}$ & -0.25 & $0.15 / 0.15$ & 0 & 1080 \\
\hline
\end{tabular}

Abbreviations: AXL, axial length; BCVA, best-corrected visual acuity measured at E chart; D, diopter; IOL, intraocular lens; PC, posterior capsule; y, years old

Table 2: Comparison of different types of CBS according to timing and mechanism 


\begin{tabular}{|c|c|c|c|}
\hline & Intraoperative & Acute CBS & Late (proliferative) CBS \\
\hline $\begin{array}{l}\text { Other } \\
\text { synonyms }\end{array}$ & Hyperacute & Noncellular, inflammatory & Fibrotic \\
\hline Onset & Immediately & Days & Months to years \\
\hline $\begin{array}{l}\text { Possible } \\
\text { cause }\end{array}$ & Hydrodissection & $\begin{array}{l}\text { Retained viscoelastics, inflammatory } \\
\text { materials }\end{array}$ & $\begin{array}{l}\text { Lens epithelial proliferation, } \\
\text { fibrosis }\end{array}$ \\
\hline $\begin{array}{l}\text { Clinical } \\
\text { findings }\end{array}$ & $\begin{array}{l}\text { Capsular bag distension and lens anterior } \\
\text { displacement }\end{array}$ & $\begin{array}{l}\text { Pupillary membrane, myopic change, } \\
\text { elevated IOP, shallow AC, ciliary body } \\
\text { rotation }\end{array}$ & $\begin{array}{l}\text { Fibrotic membrane, Elschnig } \\
\text { pearl, } \\
\text { crystaline aggregation }\end{array}$ \\
\hline Complication & Capsular tear & Decreased vision, angle closure & $\begin{array}{l}\text { Decreased vision or visual } \\
\text { quality }\end{array}$ \\
\hline \multirow[t]{2}{*}{ Treatment } & \multirow[t]{2}{*}{$\begin{array}{l}\text { Release of blockage fluid by manipulation } \\
\text { in surgery }\end{array}$} & $\begin{array}{l}\text { Anti-inflammatory drugs, } \\
\text { anterior chamber irrigation, }\end{array}$ & $\begin{array}{l}\text { YAG laser capsulotomy, } \\
\text { aspiration, Vitrecotmy }\end{array}$ \\
\hline & & YAG laser capsulotomy & \\
\hline
\end{tabular}

Table 3: Comparison of clinical characteristics in different subtypes of CBS

\begin{tabular}{|lllll|}
\hline & $\begin{array}{l}\text { Minimally opaque } \\
(\mathbf{n = 4})\end{array}$ & $\begin{array}{l}\text { Uniformly turbid } \\
(\mathbf{n}=7)\end{array}$ & $\begin{array}{l}\text { Focally condensed } \\
(\mathbf{n}=5)\end{array}$ & $\begin{array}{l}\text { Diffused sparkling } \\
(\mathbf{n}=\mathbf{2})\end{array}$ \\
\hline Age & $77.5 \pm 6,34$ & $79.86 \pm 11.26$ & $81 \pm 5.18$ & $79 \pm 13$ \\
\hline Interval btw CBS and cataract op & $54.75 \pm 34.82$ & $90.71 \pm 42.57$ & $79.8 \pm 29.88$ & $96 \pm 12$ \\
\hline AXL & $22.67 \pm 0.47$ & $24.33 \pm 1.60$ & $23 \pm 0$ & $23 \pm 0$ \\
\hline Distance of IOL and PC & $401.25 \pm 64.74$ & $516.29 \pm 101.53$ & $467.8 \pm 62.11$ & $532.5 \pm 97.5$ \\
\hline Refraction shift & $-0.1875 \pm 0,27$ & $0.05 \pm 0.06$ & $-0.325 \pm 0,71$ & $-0.188 \pm 0.06$ \\
\hline Absolute Refraction shift* & $0.31 \pm 0.11$ & $0.05 \pm 0.06$ & $0.68 \pm 0.39$ & $0.19 \pm 0.06$ \\
\hline Presenting VA & $0.23 \pm 0.04$ & $0.37 \pm 0.15$ & $0.3 \pm 0.06$ & $0.15 \pm 0.05$ \\
\hline Vision improve & $0.2 \pm 0.07$ & $0.19 \pm 0.08$ & $0.23 \pm 0.04$ & $0 \pm 0$ \\
\hline
\end{tabular}

${ }^{*} \mathrm{p}<0.05$

Abbreviations: AXL, axial length; btw: between; IOL: intraocular lens; PC: posterior capsule; VA: visual acuity

\section{Figures}
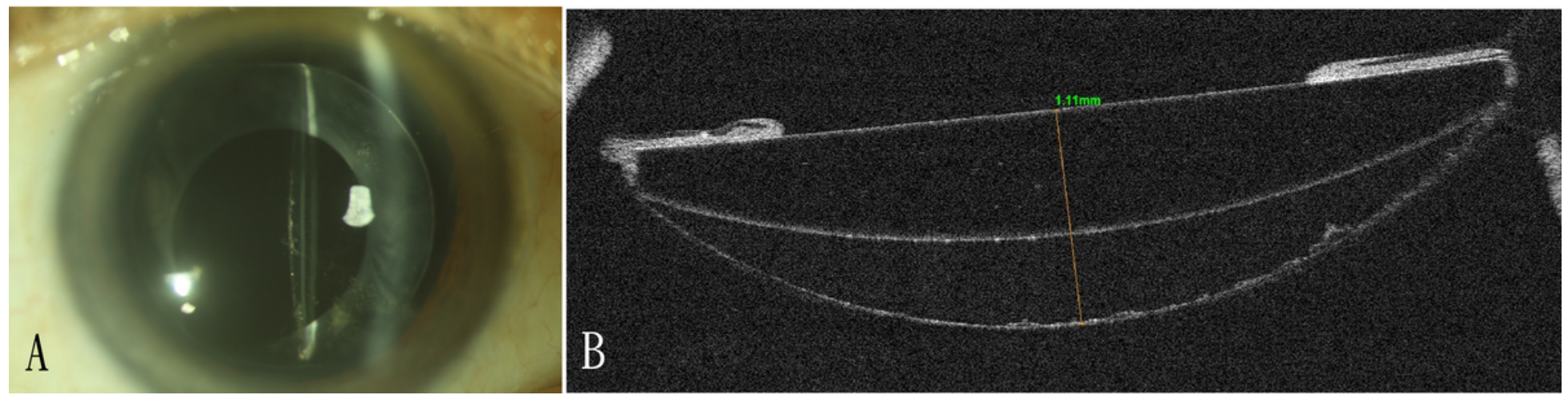

\section{Figure 1}

Minimally opaque subtype of late CBS. (A) Slit lamp shows case 1, which indicates a mild opaque fluid between the posterior surface of the intraocular lens and posterior capsule. (B) Anterior segment OCT shows a few high-signal materials coating the posterior capsular surface. 


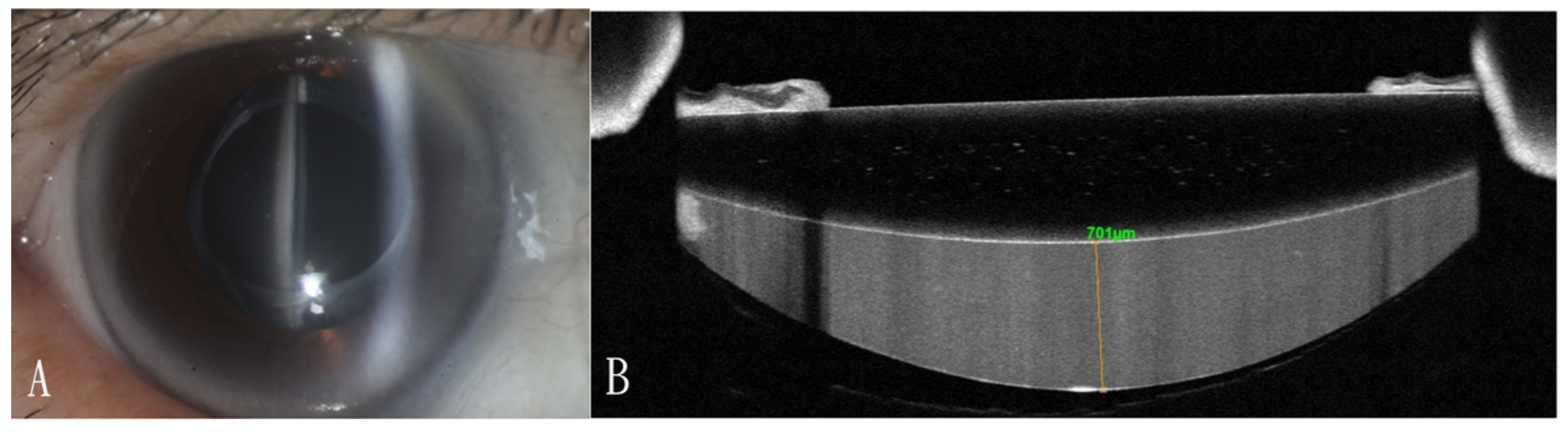

Figure 2

Uniformly turbid subtype of late CBS, case 10 (A) Slit lamp shows turbid fluid and crystalline material in the space between the intraocular lens and posterior capsule. (B) Anterior segment OCT shows compatible findings with slit lamp, reflecting medium to high signal of the turbid fluid.

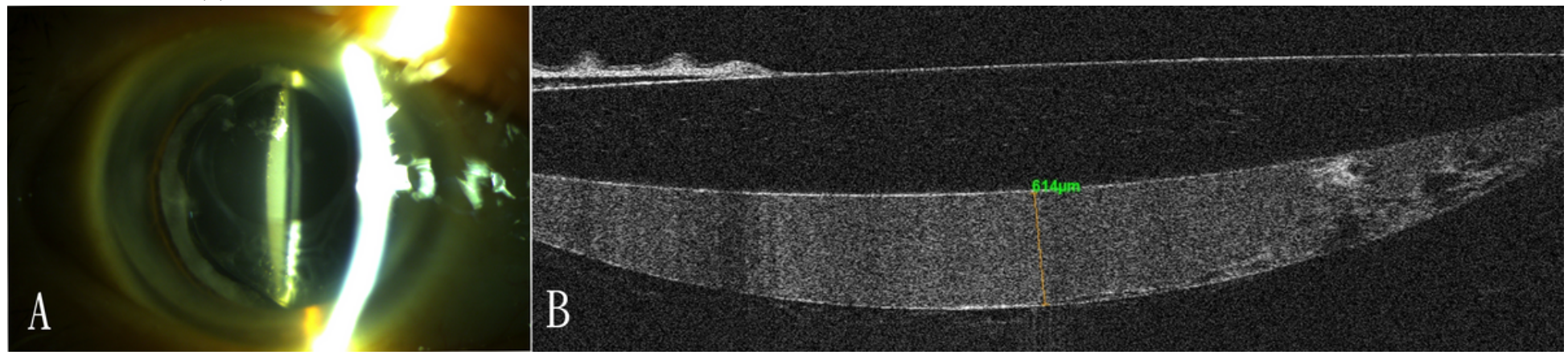

\section{Figure 3}

Focally condensed subtype of late CBS, case 9 (A) Slit lamp shows crumble-like aggregations lying periphery to the posterior capsular space. (B) Anterior segment OCT of these materials showed heterogenous reflectivity.

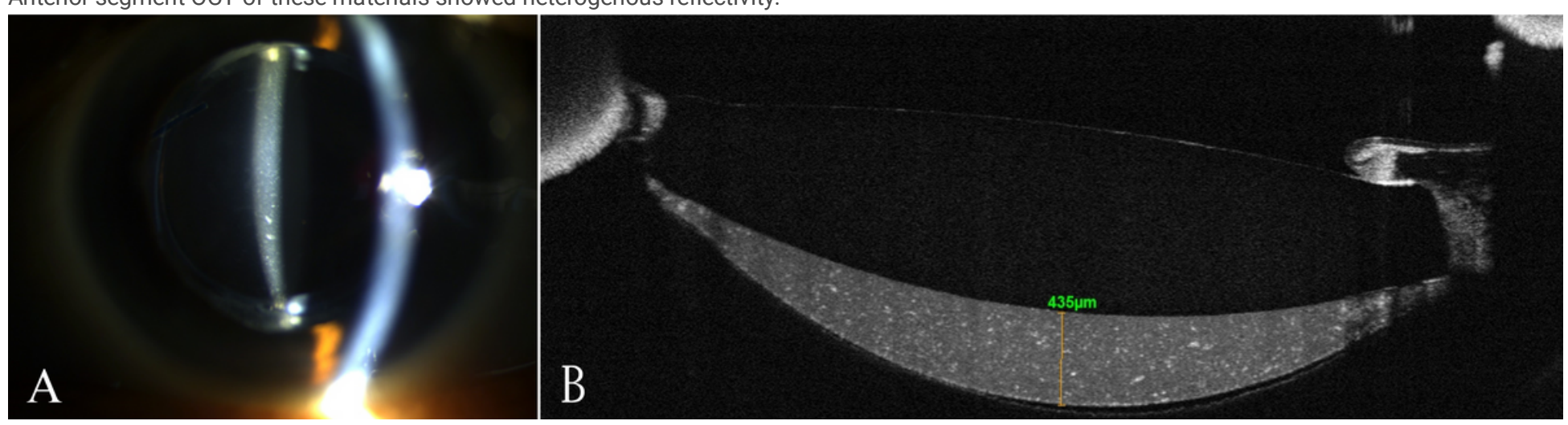

\section{Figure 4}

Diffused sparkling subtype of late CBS, case 18. (A) Slit lamp shows crystalline-like materials shining between the intraocular lens and posterior capsular space. (B) Anterior segment OCT reveals floating materials with high reflectivity. 


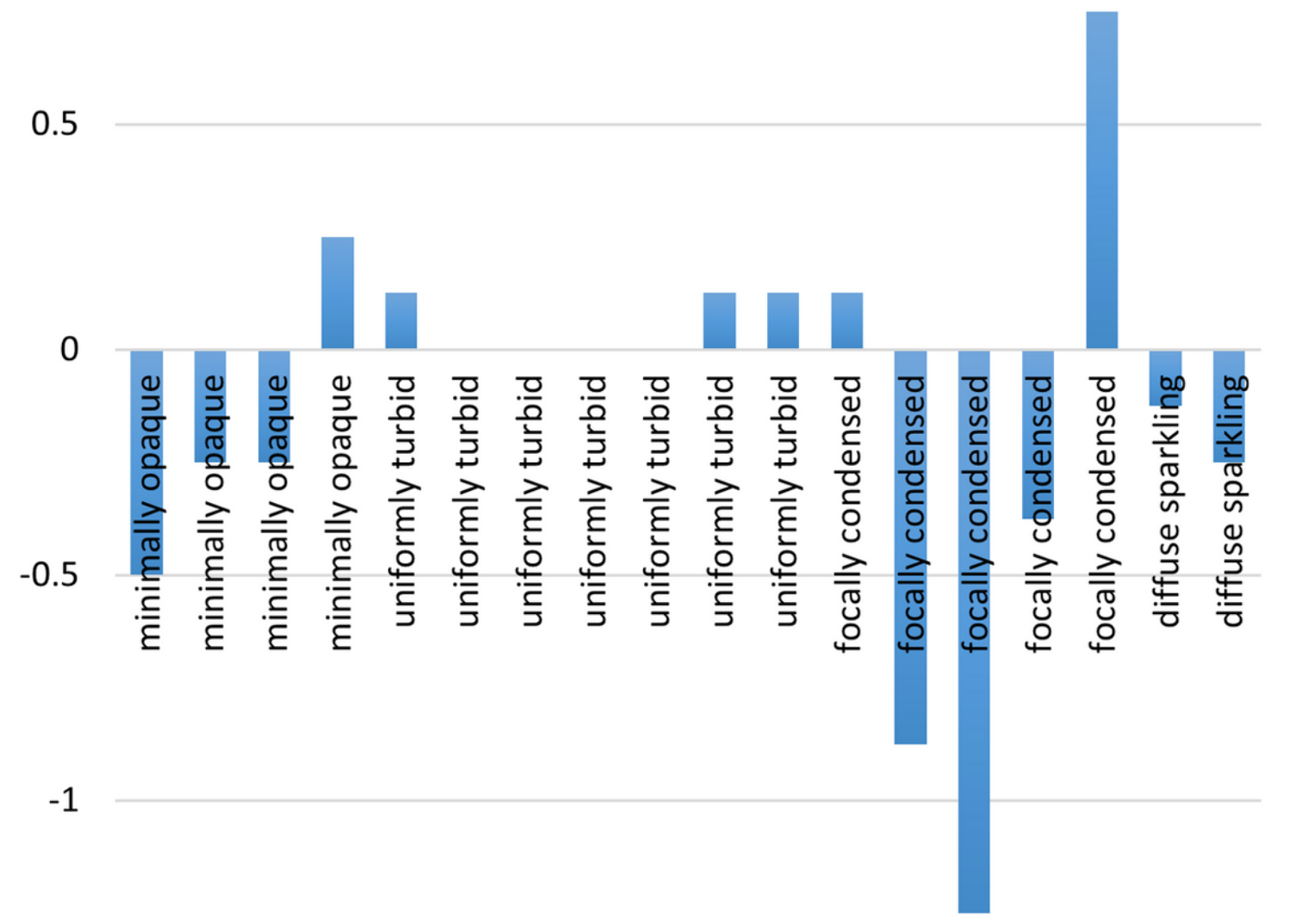

$-1.5$

Figure 5

Refraction shift after (Nd:YAG) laser capsulotomy in CBS. 